\title{
Determinants of Technical Efficiency of Small Scale Vegetables Production Under Different Irrigation Systems in Koulikoro and Mopti Regions, Mali
}

\author{
Kane Abdoulah Mamary ${ }^{1,2,}$, , Job Kibiwot Lagat ${ }^{1}$, Jackson Kipngetich Langat ${ }^{1}$, Bino Teme ${ }^{3}$ \\ ${ }^{1}$ Department of Agricultural Economics \& Agribusiness Management, Egerton University, Egerton, Kenya \\ ${ }^{2}$ Institut d'Economie Rurale (IER), Sotuba Center, Bamako, Mali \\ ${ }^{3}$ Michigan States University PROMISAM Project, Bamako, Mali
}

Email address:

kanemali2003@gmail.com (K. A. Mamary)

${ }^{*}$ Corresponding author

\section{To cite this article:}

Kane Abdoulah Mamary, Job Kibiwot Lagat, Jackson Kipngetich Langat, Bino Teme. Determinants of Technical Efficiency of Small Scale Vegetables Production Under Different Irrigation Systems in Koulikoro and Mopti Regions, Mali. American Journal of Agriculture and Forestry. Vol. 6, No. 4, 2018, pp. 71-77. doi: 10.11648/j.ajaf.20180604.12

Received: April 22, 2018; Accepted: June 3, 2018; Published: July 25, 2018

\begin{abstract}
Majority of the households in Mali depend on rain-fed agriculture for their food production. Overreliance on rainfed agriculture limit limits the production output due to unreliable rainfall in the country. To mitigate this, the government has invested in rehabilitation of irrigation schemes. Through appropriate irrigation technologies and improved agronomic management practices, agricultural productivity will be increased. The objective of this study was to determine the technical efficiency of small scale vegetables production under different irrigation systems. This study was guided by the production theory. Primary data was collected from 273 farmers selected proportionately from four wards (Fanafiecoura and Tieman, in Koulikoro region and Mopti and Dialango, in Mopti region) using face-to-face interviews. Secondary data from literature reviews was also used. Cobb-Douglas stochastic frontier production regression model was used in the analysis. Stata software was used for analysis. This study found that with respect to the production of potatoes, shallots and tomatoes, technical efficiency scores were highest in drip irrigation, followed by sprinkling irrigation and lowest in Californian irrigation system. This study recommends that drip, sprinkling Californian irrigation systems should be promoted since they presents a good opportunity for superior technical efficiency in vegetable production.
\end{abstract}

Keywords: Stochastic Frontier, Technical Efficiency, Vegetable Production, Irrigation Systems, Mali

\section{Introduction}

Most Sub- Saharan African countries are characterized by low agricultural productivity. One of the reasons for poor production is that African agriculture is predominantly rainfed, which is in most cases unreliable resulting in poor yields and the changing weather conditions would further exacerbate the situation, exposing smallholders to negative impact of climate change [1]. It is becoming increasingly evident that required food supplies cannot be met by rain fed conditions alone [2]. Agricultural activities are engaged by 80 percent of Mali's population. It therefore implies that agriculture sector is the backbone of the country's economy holding great potential for steering sustainable economic growth [3]. In Mali, the economy depends on agriculture, in that the sector contributes about 36 percent of the national income which is derived from cereal, vegetable, cotton, and sugarcane [4].

However, the vegetable sector in Mali is severely underdeveloped and vegetable consumption is extremely low. But, there is enormous potential for smallholder farmers to produce more vegetable crops for domestic market and international market [5]. Vegetables are often the most important source of cash income for smallholder farmers, and indigenous vegetables provide an important source of 
nutrition, particularly for poor people [5]. New varieties and improved management methods have been developed and extended through training programs for research and extension workers and smallholder farmers by the rural economic institute (IER) and its partner organization the World Vegetables Center (WorldVeg).

Vegetable production in Mali is affected by a number of challenges arising from climate change. Some of the most visible consequences are the declining groundwater from the months of January to February which comes at a crucial time for horticultural crops, and this limits the growing of fruits and vegetables in several localities. The immediate impact is a reduction in crop yield by up to 50 percent in rain fed agriculture [1].

Due to sinking water levels, the use of manual pumps in deep wells in some areas is no longer sustainable. It has been argued that one strategy which would be used to mitigate water scarcity and dependence on rain fall is irrigation. [6], revealed that investing in small scale irrigation schemes is one of the strategies to improve production levels especially for small holder farmers. The general belief is that irrigated agriculture limits crops failure, external shocks and increases yield thus leading to better food security $[7,8]$.

Malian government has over the years endeavored to expand the country's irrigation infrastructure in order to improve agricultural production and enhance food security. The aim was to bring about a large expansion of the total irrigated area. Before the year 2008, Dougabougou and Siribala sugar cane plantations was the only irrigated large scale land in Mali. Currently the government of Mali is implementing food sustainability for smallholder farmers through a long term national program for food security by 2025. This may be attained by targeting small scale irrigation systems to increase production.

The types of irrigation technologies that are practiced in Mali are: drip irrigation, Californian system, sprinkling system and gravity system. The Drip irrigation technology consists of bringing water under pressure in a system of pipelines. This water is then distributed in drops in the field by a large number of gutters distributed all along rows of plants. This irrigation system is used to grow tomato, onion, shallot (Allium fistulosum), banana, papaya and oranges.

Californian irrigation system is a network of Polyvinyl chloride (PVC) pipelines buried that permits to decrease losses by infiltration. It routes water to a parcel of land located away from the source of the water or having an irregular topography, and follow the level of triage and of row without addition or manipulation of hose pipes. Water is lifted from the surface or the underground water source and distributed to plants into furrows. With this system, crops are arranged on ridges. This system is mainly used for vegetable crops such as shallot and onion.

Sprinkling irrigation system is a technique of irrigation by aspersion is conceived on the model of the natural rain. Water is driven back under pressure in a network of conducts and then it is distributed by the rotary aspersers under the form of artificial rain. It is practiced on commercial farms on high value crops such as fruit trees, coffee, sugar cane, potato and horticultural crops.

The main impact of irrigation expansion is increase in the value of agricultural output in form of increased yields per ha per year (cropping intensity) and through changing the structure of agricultural output towards crops that have a yield per hectare. The increased productivity (profitability) and welfare (incomes) of households as related to improved water, irrigation, crop management, and labor will be assessed. This will determine the best combination of technology and/or crop diversification that will help in improving the overall livelihood of rural farmers.

\section{Methodology}

\subsection{Study Area and Sampling Technique}

Mali is a landlocked country in West Africa, lying between latitudes $10^{\circ} 34^{\prime} \mathrm{N}$ and $25 \mathrm{~N}$ and longitudes $4^{\circ} \mathrm{E}$ and 160 19 "W. It is the eighth- largest country in Africa, with an area of over 1,240,000 square kilometers and a population of 18 million [9]. The country's economy centers on agriculture and fishing. The research design used in this study was a survey. The target population comprised of all the small scale farmers in the selected regions. A multistage sampling procedure was used to select 273 farming households of local irrigation scheme in the three regions. The first stage was to purposely select three regions; Fanafiecoura, Tieman and Dialango on the basis of the fact that they are within the area mapped for vegetable crops and the incidence of irrigation systems. The second stage involved the use of stratified sampling where the strata included the different irrigation technologies engaged by vegetable farmers. Random sampling was used to select respondents distributed as shown in Table 1. The different irrigation technologies were: $T_{1}$ (Drip irrigation system), $\mathrm{T}_{2}$ (Sprinkling) and $\mathrm{T}_{3}$ (Californian irrigation system).

Table 1. Distribution of respondents.

\begin{tabular}{|c|c|c|c|c|c|c|c|}
\hline \multirow{2}{*}{ Enterprises } & \multicolumn{3}{|c|}{ Different Irrigation Technologies } & \multirow[t]{2}{*}{ Population } & \multirow[t]{2}{*}{ Sample size } & \multirow[t]{2}{*}{ Proportion (\%) } & \multirow[t]{2}{*}{ Location } \\
\hline & $\mathbf{T}_{1}$ & $\mathbf{T}_{2}$ & $\mathbf{T}_{3}$ & & & & \\
\hline Tomato & 31 & 31 & 31 & 3923 & 93 & 34.0 & Tiema \\
\hline Potato & 30 & 30 & 30 & 2727 & 90 & 33.0 & Fanafiecoura \\
\hline Shallot & 30 & 30 & 30 & 3549 & 90 & 33.0 & Dialango \\
\hline Total & 91 & 91 & 91 & 10,200 & 273 & 100.0 & \\
\hline
\end{tabular}

Source: [10, 11]; Shallot or Allium fistulosum

A total of 273 respondents were interviewed. 


\subsection{Methods of Data Analysis}

In this study Cobb-Douglas stochastic frontier production regression model $[12,13,14]$ was used to determine the technical efficiency of small scale vegetables production under different irrigation systems.

Stochastic Frontier Production Functions is mostly used in the identification of the best practice technology against which the efficiency of other firms within the industry can be measured. Frontier models also provide firm specific efficiency measures.

The model is specified as:

$Y_{i t}=X_{i t} \beta+\left(V_{i t}-U_{i t}\right) i=1, \ldots, N ; t=1, \ldots, T$,

Where:

$Y_{i t}$ is the vegetable production output (or its transformation) of the $\mathrm{i}^{\text {th }}$ firm in year $\mathrm{t}$;

$\mathrm{X}_{\mathrm{it}}$ is a $\mathrm{k} \times 1$ vector of inputs (or their transformations) of the $\mathrm{i}^{\text {th }}$ firm in year $\mathrm{t}$;

$\beta$ is a $1 \times \mathrm{k}$ vector of unknown parameters;

$\mathrm{V}_{\text {it }}$ is a vector of random variables as $\mathrm{N}\left(0, \sigma_{\mathrm{v}} 2\right)$ and independent of and $U_{i t}$

$\mathrm{U}_{\mathrm{it}} \geq 0$ is a vector of normal random variables truncated at zero as $\mathrm{N}\left(\mathrm{m}_{\mathrm{it}}, \sigma_{\mathrm{u}} 2\right)^{1}$.

$\mathrm{U}_{\text {it }}$ is a non-negative random variable associated with 1 firm-specific factors which contribute to may contribute to the i-th firm non-attainance of maximum efficiency of production and $V_{i t}$ is the random error.

The term $m_{i t}=Z_{i t} d$ defines an index of technical inefficiency, where $Z_{i t}$ is a $1 \times p$ vector of variables which may influence the efficiency of a firm, and $d$ is a $p \times 1$ vector of parameters to be estimated. These parameters indicate the impacts of variables in $Z$ on technical efficiency. A negative value suggests a positive influence and vice versa. The empirical model was:

$$
\begin{gathered}
\ln \left(\mathrm{Y}_{\mathrm{it}}\right)=\beta_{0}+\beta_{1} \ln \left(\text { land }_{\mathrm{it}}\right)+\beta_{2}\left(\mathrm{P}_{1} \operatorname{land}_{\mathrm{it}}\right)+\beta_{3} \ln \left(\text { labor }_{\mathrm{it}}\right)+\beta_{4} \ln \left(\text { fertilizer }_{\mathrm{it}}\right)+\beta_{5} \ln \left(\text { input }_{\mathrm{it}}\right)+ \\
\beta_{6} \ln \left(\text { water }_{\mathrm{it}}\right)+\beta_{7} \ln \left[\max \left(\text { cost }_{\mathrm{it}}, 1-\mathrm{P}_{\mathrm{it}}\right)\right]+\beta_{8}\left(\text { year }_{\mathrm{it}}\right)+\left[\mathrm{V}_{\mathrm{it}}-\mathrm{U}_{\mathrm{it}}\right]
\end{gathered}
$$

The Stochastic Frontier Production Function, [6] recommended such a model in analysis of panel data. The word 'frontier' is consistent with the theoretical definition of a production, cost, and profit function, a solution to a maximum and minimum problem, and there are two main benefits that result from estimating frontier functions. First, when a frontier function is estimated, the result is strongly influenced by the best performing firm, and therefore the frontier reflects the technology set that the most efficient firm employs. Second, frontier functions provide a useful performance benchmark. These functions normally represent best practice technology against which the efficiency of other firms within the industry can be measured. Frontier models also provide firm specific efficiency measures to the researcher. The software Statistical Package for Social Sciences (SPSS) and Excel was used in data entry, cleaning and analysis to characterize the production systems and small scale irrigation technologies and to determine the technical efficiency of small scale vegetables production under different irrigation systems.

Table 2. Description of Variables used in the Multiple Regression Model.

\begin{tabular}{lll}
\hline Variable Code & Full identity & Measurement \\
\hline Age & Age in years & Years \\
Gend & Sex of household head & $1=$ Male, $0=$ Female \\
FrmSz & Household farm size & Hectare \\
HHSiz & Household Size & Numbers \\
EducLvl & Level of education & Years \\
LandTen & Land Tenure & $1=$ Owned, $2=$ Family, $3=$ Rented \\
OfFarmInc & Off farm Income & $1=$ Yes, $0=$ No \\
CrdtAcs & Credit access & $1=$ Yes, $0=$ No \\
ExtnS & Extension Services & Accessibility to agricultural extension services \\
MrktDst & Distance to the Market & Kilometers \\
MrktInfo & Market Information & Formal or informal access to market information \\
OutptLev & Output Level & Kilograms \\
PrOutpt & Price of output & Fcfa \\
OutptGrd & Output grading & $1=$ Yes, $0=$ No \\
\hline
\end{tabular}

\section{Results and Discussions}

\subsection{Production Systems and Small Scale Irrigation Systems Characteristics}

Majority of the household heads were male $(90.7 \%)$ and only a small proportion being female $(9.3 \%)$ in terms of gender distribution. This implies that majority of the farming decisions such as use of irrigation systems may have been dominated by the male gender. This implies that any measures put to ensure gender balance in economic activities often place more emphasis to supporting men than women [15]. Involvement of both men and women in economic activities is the key to successful gender mainstreaming [16]. Women are increasingly being seen as active agents of change and the dynamic promoters of social transformations that can alter the life of all members in the society. According to [17] the exclusion of women in decision making not only 
delays delivery of benefits but also affects equity and institutional efficiency. Gender sensitivity is therefore important when investigating decision making at household level. The low possession of land by females is due to cultural marginalization that limits their rights of accessing land. Level of formal education plays a major influence in farming.

Majority $(47.6 \%)$ of the farmers were illiterate with no formal education (Figure 1). In addition to this, education of a farmer is also correlated to their agricultural skills such as production and marketing [18]. [19], revealed that illiteracy is a major constraint magnifying the state of poor performance in agricultural activities.

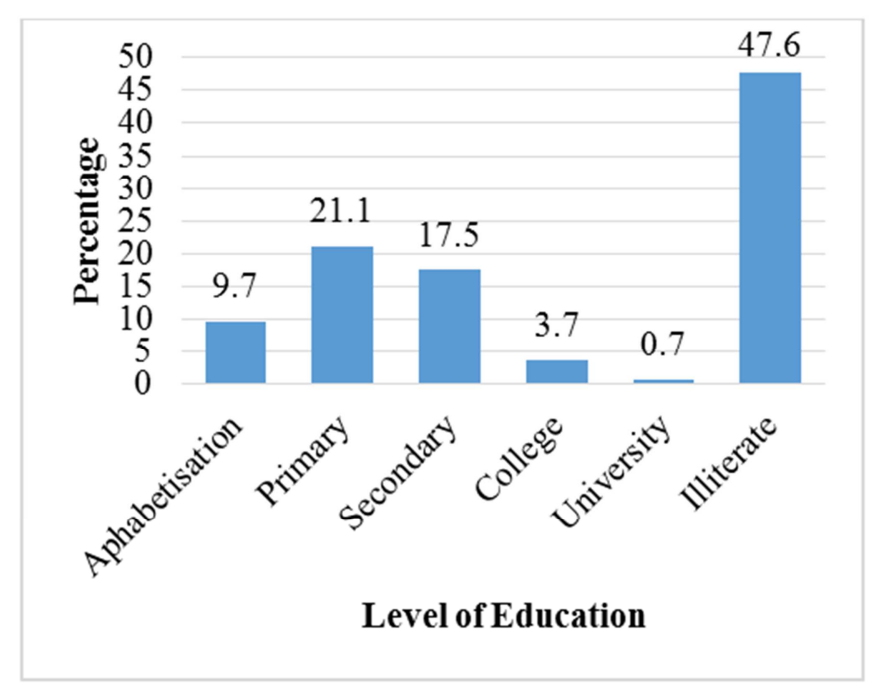

Figure 1. Level of education of the head of the household.

The farmers are mostly engaged in crop and livestock agriculture as their main occupation as represented by $37.9 \%$. About $34.1 \%$ were engaged in crop production while livestock was practiced by only $7.6 \%$. In terms of household size, $57.2 \%$ had $4-6$ adults, $25.0 \%$ had $7-9$ adult members while $15.0 \%$ had $1-3$ adult members. It was a minority $(2.8 \%)$ of the households who had 10 adult members or more. However, the mean household size (in adult equivalent) was 5.51 and relatively similar to the national average for agricultural household which is about 5.1 [20]. It was only $4.1 \%$ of the households that had 7 members and more earning incomes from non-farming activities. This implies that the economy of the study area is dependent mainly on agriculture, with the sector contributing the highest portion of household income. This agrees with [2] that noted that agricultural activities are engaged by 80 percent of Mali's population and that majority of the population derives their incomes from agriculture. The agriculture sector is the backbone of the country's economy holding great potential for steering sustainable economic growth, confirm Minister of Agriculture (2018).

About $67.8 \%$ only had access to land that was less than 5 hectares. About 25.2\% accessed land 5 - 10 hectares while only $7.0 \%$ accessed more than 10 hectares of land. These results suggest farmers are basically smallholders. Majority of the households therefore have low land holding. This may be the major reason for choice of irrigation agriculture. [21] asserts that irrigation is not only an important tool in helping farmers insure against droughts and playing an integral role in transitions from subsistence to commercial farming but can substantially boost the production of staple foods and high-value crops, amidst low land holding. The high cost of irrigation equipment as the main challenge in irrigation $(35.7 \%)$. Other challenges were unavailability of water (25.0\%), unavailability of irrigation equipment $(21.4 \%)$, difficulty in using irrigation equipment $(10.7 \%)$ and high maintenance cost $(7.1 \%)$ as the major challenges in their implementation of irrigation farming (Figure 2).

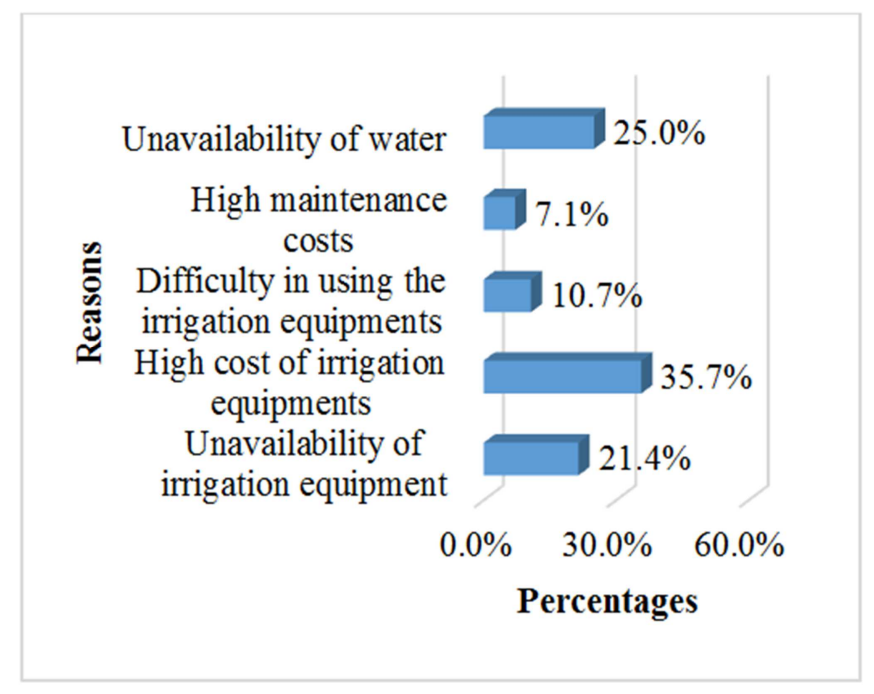

Figure 2. Reasons for non-practice of irrigation.

Drip irrigation was practiced on an average of 0.49 Hectares (with a standard deviation of 0.70 Hectares). Other irrigation systems that were practiced by respondents included sprinkling $(0.41 \mathrm{Ha}$ with a standard deviation of $0.69 \mathrm{Ha})$, Californian $(0.32 \mathrm{Ha}$ with a standard deviation of $0.16 \mathrm{Ha})$, canal IP $(0.34 \mathrm{Ha}$ with a standard deviation of 0.19 $\mathrm{Ha})$ and manual $(0.42 \mathrm{Ha}$ with a standard deviation of 0.45 $\mathrm{Ha})$.

\subsection{Technical Efficiency of Small Scale Vegetables Production under Different Irrigation Systems}

The objective of this study was to determine the technical efficiency of small scale vegetables production under different irrigation systems. It was analyzed using CobbDouglas stochastic frontier production regression model [12, $5,6]$.

\subsubsection{Ordinary Least Square Estimates of Cobb Douglas Production Function}

The efficiency estimates of the irrigation systems were measured using a Cobb Douglas stochastic frontier production model [22]. A two-step process was employed to find out the technical efficiency using maximum-likelihood method. In the first step, the ordinary least square (OLS) estimates of the parameters were obtained. The obtained 
estimates were used to estimate the maximum-likelihood estimates of the parameters treated as the frontier estimates of Cobb Douglas stochastic frontier production model during the second stage. Table 3 shows the OLS estimates of the parameters in the model.

Table 3. OLS Estimates of Cobb Douglas Production Function.

\begin{tabular}{llll}
\hline Variables & Coefficients & Std. Error & t-value \\
\hline Constant & $0.786^{*}$ & 0.116 & 6.776 \\
Seeds & $0.146^{*}$ & 0.034 & 4.294 \\
Manure & 0.143 & 0.109 & 1.312 \\
Fertilizers & $0.246^{*}$ & 0.083 & 2.964 \\
Pesticides & 0.123 & 0.157 & 0.783 \\
Labor & $0.265^{*}$ & 0.131 & 2.023 \\
Transportation & 0.041 & 0.074 & 0.554 \\
Sigma-squared & 0.538 & & \\
\hline
\end{tabular}

From the analysis, the coefficient of seed cost was significant at $5 \%$ level with a value of 0.146 . The coefficients for costs of fertilizers $(0.246)$ and labour $(0.265)$ were also significant at $5 \%$ level. However, the coefficients for cost of manure $(0.143)$, pesticides $(0.123)$ and transportation $(0.041)$ were insignificant at $5 \%$ level. The parameter $\sigma$ was positive, which indicates that the observed output differed from frontier output.

\subsubsection{Maximum-Likelihood Estimates of Cobb Douglas Production Function}

Table 4 presents the maximum-likelihood estimates of the parameters of Cobb Douglas stochastic frontier production model.

Table 4. OLS Estimates of Cobb Douglas Production Function.

\begin{tabular}{llll}
\hline Variables & Coefficients & Std. Error & t-value \\
\hline Constant & $0.995^{*}$ & 0.196 & 5.071 \\
Seeds & $0.549^{*}$ & 0.144 & 3.807 \\
Manure & 0.166 & 0.118 & 1.401 \\
Fertilizers & $0.067^{*}$ & 0.008 & 8.519 \\
Pesticides & 0.031 & 0.292 & 0.107 \\
Labor & $0.056^{*}$ & 0.011 & 5.333 \\
Transportation & 0.075 & 0.371 & 0.203 \\
Sigma-squared & $0.042^{*}$ & 0.005 & 8.061 \\
Gamma & 0.014 & 0.010 & 1.412 \\
Eta & $0.956^{*}$ & 0.291 & 3.289 \\
\hline
\end{tabular}

From the analysis, the coefficients of costs of seeds, fertilizers and labour were significant at 5\% level, with values of $0.549,0.067$ and 0.056 , respectively; indicating that the crop yield (output) was explained by $54.9 \%$ of seed costs, $6.7 \%$ of fertilizer costs and $5.6 \%$ of labour costs. On the other hand, the coefficient of cost of manure, pesticides and transportation was found to be insignificant with a value of $0.166,0.031$ and 0.075 indicating that the output variable was explained only by $16.6 \%$ of manure costs, $3.1 \%$ of pesticides costs and $7.5 \%$ of transportation costs. The coefficient of seed costs showed a positive sign, indicating that farmers who spend more on quality seeds realize more yields and are more productive. In the same way, the coefficients for fertilizer and labour costs were also positive, indicating that greater use of these inputs significantly result to higher production.
The value of $\gamma$ (Gamma) was estimated to be 0.014 , which demonstrates that 1.4 percent variations in output among the irrigation systems were due to the differences in technical efficiency. It is also evident from the results that the estimate of gamma (0.014), which is significantly different from zero, indicating a good fit. As the estimates for the $\eta$ (eta) parameter were observed to be positive, it can be concluded that the technical inefficiency effects tend to decrease.

\subsubsection{Comparison of Technical Efficiency under Different Irrigation Systems}

This section attempts to ascertain the existence of difference (or otherwise) in technical efficiencies scores of the three major types of irrigation technologies practiced in the study area.

Knowledge about the relative efficiencies of vegetable production with varied types of irrigation technologies is of importance and worth investigation. The performance of drip, sprinkling and Californian irrigation systems in terms of pure technical efficiency is presented in Table 5 and their comparison illustrated.

Table 5. Average pure technical efficiency scores of vegetable production under different irrigation systems.

\begin{tabular}{llll}
\hline Crop & Drip & Sprinkling & Californian \\
\hline Potatoes & 89.14 & 90.88 & 76.35 \\
Shallots & 92.67 & 90.53 & 78.79 \\
Tomatoes & 93.22 & 90.26 & 75.46 \\
Average & 91.68 & 90.56 & 76.87 \\
\hline
\end{tabular}

Calculated F-Ratio $_{(2,269)}=76.78$, P-value $<0.05$, Critical F-Ratio $(2,269)=$ 3.03

The results demonstrate an overall variation in pure technical efficiency scores under different irrigation systems (the mean pure efficiency scores differs across the irrigation systems).

With respect to the vegetable production of potatoes, shallots and tomatoes, this study noted that the pure technical efficiency scores were highest in drip irrigation (91.68) and followed by sprinkling irrigation (90.56). The pure technical efficiency scores were lowest in Californian irrigation system (76.87).

However, a closer look at Bonferroni multiple comparison test reveals a non-existence of difference between drip and sprinkling irrigation technologies (Table 6).

Table 6. Comparison of technical efficiencies of irrigation systems using Bonferroni multiple comparison test.

\begin{tabular}{lll}
\hline & Drip & Sprinkling \\
\hline Irrigation technologies & Mean diff (P-value) & Mean diff (P-value) \\
Sprinkling & $-1.12(0.561)$ & - \\
Californian & $-14.81(0.000)$ & $-13.69(0.000)$ \\
\hline
\end{tabular}

The mean difference in pure efficiency scores of drip and sprinkling irrigation systems (1.12) is not significant at $5 \%$ level. The mean difference in pure efficiency scores existing between drip and Californian irrigation system (14.81) as well as between sprinkling and Californian irrigation systems (13.69) is significant at 5\% level as can be observed from P- 
values of $<0.05$ and $<0.05$, respectively. This implies that both drip and sprinkling irrigation technologies make better use (economical) of inputs in their production as compared to Californian, that is, they utilize less input costs (than the Californian system) for same level of output.

With respect to pure technical efficiency of use of drip irrigation technology on vegetable production, this study observed that drip irrigation is most efficient in production of tomatoes (93.22) and followed by shallots (92.67) as shown in Table 7. Drip irrigation is least efficient in production of potatoes (89.14). The difference in efficiency scores of drip irrigation on production of selected horticultural crops was significant at $5 \%$ level ( $\mathrm{p}$-value $<0.05$ ).

Table 7. Technical efficiency scores of different irrigation technologies on vegetable production.

\begin{tabular}{llllll}
\hline Crop & Potatoes & Shallots & Tomatoes & F-Ratio & P-value \\
\hline Drip & 89.14 & 92.67 & 93.22 & 6.43 & 0.001 \\
Sprinkling & 90.88 & 90.53 & 90.26 & 2.94 & 0.121 \\
Californian & 76.35 & 78.79 & 75.46 & 4.27 & 0.001 \\
Average & 85.46 & 87.33 & 86.31 & & \\
\hline
\end{tabular}

Critical F-Ratio $_{(2,269)}=3.03$

As far as sprinkling irrigation was concerned, this study observed that the technology was most efficient on production of potatoes (90.88), followed by shallots (90.53) and then tomatoes (90.26). The difference in efficiency scores of sprinkling irrigation on production of selected horticultural crops was however not significant at $5 \%$ level $(p$-value $=0.121)$.

This study noted that the difference in efficiency scores of Californian irrigation technology on production of selected horticultural crops was significant at 5\% level ( $p$-value $<0.05$ ). Californian irrigation technology was most efficient on production of shallots (78.79), followed by potatoes (76.35) and then tomatoes (75.46).

\section{Conclusion}

Majority of the farming decisions such as use of irrigation systems are dominated by male gender. Most farmers lack adequate formal education which is necessary for better modern farming. The most popular occupation practiced in the study area is agriculture (crop and livestock). The household sizes in the study area are relatively similar to the 5.1 national averages for agricultural households. Most households have members who earn from non-farming activities. Land holdings in the area are quite low with majority of the households lacking enough land for expansion into agricultural activities. The major challenge with irrigation includes the high cost of irrigation equipment, difficulty in using irrigation equipment and high maintenance cost. Most farmers are not members of water management association. The major type of irrigation systems practiced in the study area include drip, sprinkling, Californian, canalGravity/IP and manual irrigation systems.

The cost of seeds, fertilizers and labour were significant at 5\% level indicating that greater use of these inputs significantly results to higher production. About 1.4 percent variations in output among the irrigation systems was due to the differences in technical efficiency. With respect to the vegetable production of potatoes, shallots and tomatoes, this study noted that the pure technical efficiency scores are highest in drip irrigation, followed by sprinkling irrigation and lowest in Californian irrigation system. Drip irrigation was most efficient in production of tomatoes, followed by shallots and least efficient in production of potatoes. Sprinkling irrigation technology was most efficient on production of potatoes, followed by shallots and least efficient in tomatoes. Californian irrigation technology was most efficient on production of shallots, followed by potatoes and then tomatoes.

In view of the findings and the conclusions drawn above, this study makes the following recommendations:

The government should implement measures to ensure gender balance in economic activities. Involvement of both men and women in economic activities is the key to successful agriculture. The exclusion of women in decision making often delays delivery of benefits from agriculture. The lack of adequate formal education necessary for better modern farming should be compensated by increased trainings and extension service provision. Owing to limited land holdings, the government and development agencies should strive to strengthen irrigation farming (through subsidies, tax holidays and grants) in the study area. These benefits can be easily harnessed through farmers' membership to water management associations.

Drip, sprinkling Californian irrigation systems presents a good opportunity for superior technical efficiency in vegetable production. These irrigation technologies should be promoted. Drip irrigation should be promoted more in production of tomatoes and shallots as compared to potatoes while sprinkling irrigation technology should be promoted more on production of potatoes and shallots as compared to tomatoes. Californian irrigation technology should be promoted more on production of shallots and potatoes as compared to tomatoes.

\section{Acknowledgements}

This material is based upon work supported by the Consultative Group for International Agricultural Research (CGIAR) and the United States Agency for International Development (USAID), as part of the Feed the Future initiative, under the CGIAR Fund, award number BFS-G-1100002, and the predecessor fund the Food Security and Crisis Mitigation II grant, award number EEM-G-00-04-00013. 


\section{References}

[1] Todaro, M. P., and Smith. S. C. (2012). Economic Development policy 11th Edition. New York University. Developing Countries Economic Policy. Boston: Adisonwesley Publishers USA, 2012.

[2] PCDA. (2009). Ministry of Agriculture (MOA) 2013. Budget and Performance Report, Mbabane, Swiziland: MOA, 2013.

[3] USAID (2018). Agriculture and Food Security. Retrieved from https://www.usaid.gov/mali/ agriculture-and-food-security.

[4] National Report Ministry of Agricultural. (2013). Ministry of Agriculture (MOA) 2013. Budget and Performance Report, Mbabane, Swiziland: MOA.

[5] World Veg. (2013). AVRDC Highlighting horticulture in Mali, USAID-Mali project: "Improving Vegetable Production and Consumption in Mali." Available at: https://avrdc.org/highlighting-horticulture-mali/.

[6] Hussain, I. (2004). Pro-Poor Intervention Strategies in Irrigated Agriculture in Asia: Poverty in Irrigated Agriculture. Realities Issues Options and Guidelines. India, pakistan, Vietnam and Banglasdesh. International water management institute.

[7] Nokuphiwa L. Sithole, Job K. Lagat, and Micah B. Masuku. (2014) "Factors influencing Farmers Participation in Smallholder Irrigation Schemes: the case of Ntfonjeni Rural Development Area. Journal of Economics and Sustainable Development, 5 (22):159-167.

[8] FAO (2010). How design, management and policy affect the performance of irrigation. Rome: FAO, n.d.

[9] UNDESA (2017). World Population Prospects: The 2017 Revision". ESA. UN. org (custom data acquired via website). United Nations Department of Economic and Social Affairs, Population Division.

[10] DNSI, Report RGA. (2005). DNSI (Direction National de la Statistiques et de l'Informatique)., Schéma directeur statistique. Draft version, Bamako: DNSI, 2005.

[11] Kelly, V. (2008). Agricultural Statistics in Mali: Institutional Organization and Performance. Background paper for the World Bank (WB) on agricultural. Washington D. C: World Bank.
[12] Coelli, G. E., and Bettes T. J. (1995). A Model for Technical Inefficiency Effects In a stochastic frontier Production Function For Panel Data. Empirirical Economics, 1995: 325332.

[13] Coeli, J. T. (1995). Recent development in frontier modelling and efficiency measurement department of Econometrics university of New England, Armidale NSW. Australian Journal of Agriculture Economics, 39 (3), 219-245.

[14] Battese T. J, and Coelli, G. E. (1993). Frontier Production Function incorporating a model for technical ineficiency effects: Working papers Inn econometrics and applied statistics No 69. Armidale: University of New England, 1993.

[15] World Bank. (2009). Gender dimensions of the extractive industries. Washington, DC: The World Bank.

[16] Guslits, B., \& Phartiyal, J. (2010). Women \& water in the age of globalization: Protecting our most vital resource. Women \& Environments International Magazine (82/83), 12-14.

[17] Nyanjom, O. (2011). Devolution in Kenyans' new constitution. Constitution Working Paper Series no. 4. Nairobi: Society for International Development.

[18] Perry, J., \& Johnson, J. (1999). What makes a small farm successful? Economic Research Service-USDA. Agricultural Outlook, November.

[19] World Bank (2009). Gender dimensions of the extractive industries. Washington, DC: The World Bank.

[20] IER. (2017). Institut d'Economie Rurale (Rural Economic Institute): Feed the Future Innovation Lab for Food Security Policy. Semi Annual Report: October 2016 - March 2017 (Award AID-OAA-L-13-00001).

[21] Kay, M (2001). Smallholder irrigation technology: prospects for sub-Saharan Africa, International Programme for Technology and Research in Irrigation and Drainage (IPTRID), Rome: Food and Agriculture Organization of the United Nations.

[22] Battese, G. E. \& Coelli, T. J. (1992). Frontier production functions, technical efficiency and panel data: with application to paddy farmers in India. Journal of Productivity Analysis 3, 153-169. 